\title{
HARMONIA VOCÁLICA EM REGISTROS ESCRITOS ANTIGOS DO PORTUGUÊS
}

\section{VOWEL HARMONY IN ANCIENT PORTUGUESE WRITTEN TEXTS}

\author{
Evellyne Patrícia Figueiredo de Sousa Costa \\ Universidade Federal de Santa Maria, UFSM, Santa Maria, RS, Brasil \\ Tatiana Keller \\ Universidade Federal de Santa Maria, UFSM, Santa Maria, RS, Brasil
}

\begin{abstract}
Resumo: A harmonia vocálica é comum no português moderno e, conforme Bisol (1981), bastante antiga. Diante desse fato e com base no pressuposto de que o registro escrito é um testemunho importante do comportamento de uma determinada língua em seus estágios anteriores, analisamos dados do latim vulgar até o português falado atualmente, passando por registros do português antigo, a fim de verificar a realização das vogais médias pretônicas /e/ e /o/ como /i/ e /u/ na presença de vogal alta em sílabas subsequentes. Observamos se há ocorrências desse processo em latim vulgar, o que indicaria que esse fenômeno é muito antigo.

Palavras-chave: harmonia vocálica; registro escrito; Língua Portuguesa.
\end{abstract}

Abstract: Vowel harmony is a process quite common in modern Portuguese and, according to Bisol (1981), an ancient one, as well. Given this fact and based on the assumption that written texts are an important testimony to the behavior of a given language in its earlier stages, we analyzed data from Vulgar Latin to current spoken Portuguese in order to verify if prettonic mid vowels /e/ and $/ \mathrm{o} /$ are realized as $/ \mathrm{i} /$ and $/ \mathrm{u} /$ when they are followed by high vowels in the next syllables. For this, we observed if this process occurs in Vulgar Latin, which would indicate that is a very old phenomenon.

Keywords: vowel harmony; written texts; Portuguese.

\section{Introdução}

É sabido que a instabilidade da realização das vogais médias /e, o/ como /i, u/ em posição pretônica não é característica apenas do português atual. Bisol (1981), Schwindt (2002), dente outros, já apontam que a harmonia vocálica é uma herança do português antigo. No entanto, poucas são as descrições de estágios anteriores da língua no que diz respeito a esse processo fonológico, do mesmo modo como é reduzido o número de descrições que abarquem o latim vulgar.

Partindo do pressuposto de que a língua é um continuum e de que o limite entre sincronia e diacronia pode ser dissolvido (COSERIU, 1979), acompanhamos a ocorrência de harmonia vocálica desde o latim vulgar até a atualidade. Buscamos também contribuir para a caracterização do comportamento do sistema vocálico do português. 
Na primeira seção, na fundamentação teórica, discorreremos sobre a importância do registro escrito para a pesquisa linguística e caracterizaremos o processo de harmonização vocálica em português; na segunda seção, descreveremos as fontes dos dados, bem como os critérios de coleta; na terceira seção, apresentaremos e discutiremos os resultados obtidos e, na última seção, manifestaremos as nossas considerações finais.

\section{FUNDAMENTAÇÃO TEÓRICA}

\section{O registro escrito como corpus}

É ponto pacífico que olhar para o passado é de suma importância para explicar o comportamento das línguas modernas. Estudiosos como Poggio (2002), Monaretto (2005), Castilho (2007), Berlinck, Barbosa e Marine (2008), entre outros, chamam a atenção para a importância das fontes escritas para o estudo da mudança linguística e para a explicação de fenômenos que perduram modernamente. De acordo com Poggio (2002), para estudar a mudança linguística é necessário investigar estágios linguísticos diferentes e empregar modelos e teorias desenvolvidos em pesquisas de fenômenos sincrônicos.

Conforme Weinrich, Labov e Herzog (1968), a preocupação atual com relação à mudança linguística vincula-se a sua origem, implementação e propagação; nesse sentido, busca-se responder à seguinte pergunta: como e quando as línguas mudam? Para tanto, o dado escrito é fundamental na análise de estágios antigos de uma língua.

Labov (1972) aponta para a atuação do princípio do uniformitarismo, segundo o qual mudanças ocorridas no passado podem vir a acontecer no presente, para justificar a afirmativa de que é preciso estudar o passado para melhor explicar o presente. Com relação ao uso do texto escrito para a análise da mudança, o autor diz que a investigação que toma como fonte o dado escrito é uma tentativa de fazer o melhor uso de um dado ruim (LABOV, 1972). A escrita pode apresentar características comuns à fala; entretanto, por conta do sistema ortográfico, contém registros que não são significativos linguisticamente. Por isso, para utilizar esse tipo de dado, é necessário estabelecer critérios que diferenciem questões de ortografia, caligrafia, estilo, reflexos da fala, entre outras.

Monaretto (2005), ao tratar do estudo da mudança sonora no registro escrito, chama a atenção para o fato de que, no século XIX, a mudança linguística era estudada tendo a Linguística Histórica como subsídio, isto é, o enfoque residia na reconstrução de estágios de língua, por meio dos quais formas atestadas e não-atestadas eram inferidas. Atualmente, segundo a autora, o olhar do pesquisador volta-se para a tentativa de descobrir indícios de 
variação e de tendências para determinar, a partir de registros escritos, como e quando as línguas mudam.

A autora conclui que é possível identificar e resgatar indícios de variação e de mudança com relação a alguns fenômenos fonológicos, tais como epêntese, rotacismo, harmonia vocálica, dentre outros. Para que estudos que se enquadrem nesse tipo de investigação tenham êxito, a grande preocupação deve residir na constituição do corpus e na filtragem dos dados, para que seja possível diferenciar registros significativos linguisticamente de registros que não o são.

Nesse sentido, nosso trabalho busca verificar indícios e/ou tendências de variação ou mudança em relação ao fenômeno de harmonia vocálica em português desde o latim vulgar até os dias de hoje.

\section{Harmonia vocálica}

Fernão de Oliveira (1536), no capítulo Da semelhança e proximidade de certas vozes, afirma que "as vogais / e i/ e /o u/ tem tanta vezinhença que quasi nos confundimos". O autor cita como exemplo a variação entre somir/sumir, dormir/durmir e bolir/bulir. Podemos perceber, por meio dessa observação, que o processo de harmonização vocálica já era recorrente e objeto de descrição da Língua Portuguesa.

Do ponto de vista linguístico, dizemos que, no processo de harmonia vocálica, as vogais médias /e, o/ realizam-se como /i, u/ obrigatoriamente na presença da articulação alta de uma vogal seguinte, por exemplo, coruja curuja, menino minino (BISOL, 1981). Segundo Wetzels (1992), no âmbito da Geometria de Traços, é possível afirmar que esse processo, no português brasileiro, resulta do espraiamento do traço [-aberto] da vogal alta para a vogal média da sílaba anterior e não de todo o nó vocálico. Em virtude disso, não encontramos casos como *d[i]mingo para $\mathrm{d}[\mathrm{o}]$ mingo, ${ }^{*} \mathrm{~s}[\mathrm{u}]$ gunda para $\mathrm{s}[\mathrm{e}]$ gunda, mas $\mathrm{sim}, \mathrm{d}[\mathrm{u}]$ mingo e s[i]gunda, respectivamente. Dessa maneira, a "vezinhença" entre as vogais /e, i/ e /o, u/ pode ser explicada.

No que diz respeito a estágios anteriores do português, Carvalho (1969) afirma que o condicionamento para a elevação das médias pretônicas, no português quinhentista, é a influência da vogal alta da sílaba seguinte: "o cerramento o $>\mathrm{u}, \mathrm{e}>\mathrm{i}$ estava pois submetido na linguagem quinhentista às mesmas condições em que o fenómeno hoje mesmo se observa, não ainda estabilizado, no português do Brasil" (CARVALHO, 1969, p. 95). Castro (1991) defende que o condicionamento da harmonia vocálica, em textos medievais (cantigas de Afonso X), também seja a pressão assimilatória da altura $\mathrm{da} \quad$ vogal alta acentuada $-\mathrm{d}[\mathrm{o}] \mathrm{rmir} \sim \mathrm{d}[\mathrm{u}] \mathrm{rmir} ; \quad \mathrm{m}[\mathrm{e}]$ nino $\sim \mathrm{m}[\mathrm{i}] \mathrm{nino}$; $\mathrm{d}[\mathrm{e}] \mathrm{f}[\mathrm{e}]$ ndimento $\sim \mathrm{d}[\mathrm{i}] \mathrm{f}[\mathrm{i}]$ ndimento. 
Avelheda e Silveira (2011) fazem um estudo pancrônico do comportamento das vogais médias pretônicas em português com base em corpora de textos disponíveis nos bancos de dados PHPB (Para uma História do Português Brasileiro) e VARPORT (Projeto Análise Contrastiva de Variedades do Português) para dados diacrônicos dos séculos XVIII e XIX. Dos seis casos de alteamento coletados pelas autoras (infado, cintir, sintirei, avinturei-me, incalhar, intidade), quatro casos são de harmonia vocálica (cintir, sintirei, avinturei-me, intidade). Vale ressaltar, como aponta Bisol (1981), que a ocorrência de alçamento da vogal média anterior é altamente favorecida em posição inicial, em sílaba travada ou não, independentemente do contexto seguinte. Sendo assim, teríamos apenas três exemplos de harmonização vocálica: cintir, sintirei, avinturei-me.

Avelheda e Silveira (2011) chamam a atenção também para o fenômeno de abaixamento das vogais médias pretônicas. Nos corpora das autoras foram encontrados diversos casos de abaixamento, que poderiam configurar hipercorreção, o que indicaria o processo de harmonia vocálica com a vogal média alta: emcomodo, emportância, enflamação, empreterivelmente. Casos desse tipo já são registrados por Feijó (1739), tais como: abondar, acentoar, acepelhar. Exemplos desse tipo ilustram bem a variabilidade na realização das vogais médias.

No que tange aos dados de fala concernentes à harmonia vocálica no português atual, analisados no âmbito da Teoria da Variação, citamos os trabalhos de Bisol (1981) e Schwindt (2002) com dados do português falado no sul do Brasil. Os resultados de Bisol (1981) mostram que esse fenômeno é variável, mas de baixa aplicação: $24 \%$ para /e/ e 36\% para /o/. Os resultados de Schwindt (2002) também revelam que a harmonia vocálica é um fenômeno variável, porém não estagnado, uma vez que, no período de duas décadas, o percentual de aplicação para a vogal /e/ aumentou de $24 \%$ para $36 \%$ e, para a vogal $/ \mathrm{o} /$, de $36 \%$ para $42 \%$. Os resultados do autor corroboram a afirmação de Carvalho (1969), pois ambos apontam para o fato de que a harmonia vocálica não se caracteriza como um fenômeno estagnado, mas sim como um processo recorrente.

Quando o corpus é constituído por registros escritos, é esperado que um fenômeno característico da fala, como o de harmonia vocálica, seja menos recorrente ou não seja encontrado por força de convenções ortográficas. Entretanto, se os textos tiverem sido produzidos anteriormente a um modelo de normatização ortográfica (1911, no caso da Língua Portuguesa), esse processo poderá refletir-se mais facilmente na escrita ${ }^{1}$. Por isso, neste trabalho, optamos por analisar dados anteriores a esse período.

${ }^{1}$ Antes de 1911 não havia uma normatização unificada. 


\section{PROCEDIMENTOS METODOLÓGICOS}

\section{Descrição das fontes de dados: do latim vulgar ao séc XX}

Com o objetivo de dar conta da descrição do processo de harmonia vocálica em registros antigos do latim ao português, temos como corpora básicos as seguintes fontes: (i) Appendix Probi e (ii) Orthograpbia, on a arte de escrever, e pronunciar com acerto a língua portugueza (FEIJÓ, 1739); e como corpora complementares: (iii) textos literários, tais como Diálogos de São Gregório, Cantigas de Santa Maria e outros textos extraídos do Corpus do português: 45 milhões de palavras do século XIII ao século XX (DAVIES; FERREIRA, 2006); (iv) Gramática da Lingoagem Portugueza e (v) Banco de dados Português Histórico do Rio Grande do Sul.

Para entendermos melhor uma fonte do latim vulgar como o Appendix Probi (século IV d. C), é necessário que entendamos o sermo plebeus (latim vulgar - associado ao falar popular) como uma das variedades do latim ao lado do sermo urbanus (latim urbano - variedade comumente associada à camada mais escolarizada da sociedade romana), sermo litterarius (latim literário ou clássico - essencialmente escrito), sermo castrensis (latim geralmente associado aos integrantes do exército), sermo peregrinus (latim falado pelos estrangeiros), sermo rusticus (latim rural - comumente associado à fala dos habitantes do campo $)^{2}$.

Diante desse cenário, o Appendix Probi caracteriza-se como um glossário, isto é, uma lista de palavras feita com o objetivo de corrigir erros de pronúncia de alunos. Esse glossário, de autoria desconhecida, traz uma compilação de 227 palavras corretas do latim clássico (essencialmente escrito) ao lado da pronúncia incorreta empregada na fala popular. Processos como sonorização de consoantes surdas intervocálicas, síncope, metátese e rotacismo podem ser encontrados nesses registros.

Feijó (1739) divide sua Orthographia, ou a arte de escrever, e pronunciar com acerto a lingua portugueza em três partes. A primeira versa sobre regras e preceitos ortográficos, principalmente com relação às dificuldades de grafia. $\mathrm{Na}$ segunda parte, o autor trata da separação das palavras e do uso da pontuação. $\mathrm{Na}$ terceira parte da obra, constam os erros mais comuns de pronúncia, bem como suas emendas, organizados em ordem alfabética, "como se fora um Appendix Probi do século XVIII", nas palavras de Avelheda e Silveira (2011).

Feijó justifica, no Prolegômeno da obra, a necessidade da terceira parte dizendo que:

[...] refletindo com mais atenção nos preceitos desta Orthographia, entrei a considerar, se bastariaõ elles, para sabermos escrever, e pronunciar com acerto

${ }^{2}$ Divisão feita por Basseto (2002). 
todas, ou ao menos as principáes palavras da nossa língua Portugueza? E achei que não; porque nem esta nem outra algũa nos dá regras para acertar na variedade, e mudança, que na sua conjugação tem os verbos anômalos, e irregulares, de que abunda nossa língua. Nenhũa diz como se tira a duvida em innumeraveis palavras, que saõ controversas não só nas lettras, com que se escrevem, mas nos tons, ou acentos, com que se pronunciaõ. E nenhũa ensina como se devem emendar os erros vulgáres da pronunciaçaõ commua; e por isso me resolvi a continuar com a Terceira Parte. Intitularse a Terceira Parte erros do vulgo, emendas da Orthographia no escrever, e pronunciar. E bem lhe pódes chamar hum Thesouro, ou Vocabulário Orthográphico da lingua Portugueza; porque só neste acharás o como se escrévem, e se pronunciaõ todos os vocábulos da nossa lingua, que poderiaõ causar duvida, ou nas letras, ou na pronunciaçaõ (FEIJÓ, 1739, p. 9).

Os corpora complementares constituem-se por Cantigas de Santa Maria, Diálogos de São Gregório e outros textos literários extraídos do Corpus do português: 45 milhões de palavras do século XIII ao século XX (DAVIES; FERREIRA, 2006), por gramáticos, como Fernão de Oliveira (1536), e por 20 cartas pessoais do século XIX, coletadas no estado do Rio Grande do Sul, que fazem parte do banco de dados Português Histórico do Rio Grande do Sul (PHRS) ${ }^{3}$. Essas fontes são importantes porque nos permitem acompanhar a trajetória da harmonia vocálica em intervalos menores de tempo e também verificar se há palavras em que esse fenômeno é recorrente.

\section{Critérios de seleção dos dados}

1) Período: século IV até o início do século $X X$

A escolha do Appendix Probi como fonte para descrição se deve ao fato de que esse é o primeiro registro que faz alguma referência ao latim falado. Para evitar possíveis interferências de uma normatização ortográfica estabelecida em português a partir de 1911, a coleta dos dados estende-se até o início do século XX, mais precisamente, até 1910.

2) Vogal média pretônica seguida de alta nas sílabas subsequentes

Em virtude das descrições fonológicas do fenômeno, que o caracterizam como uma assimilação regressiva de altura vocálica, optamos por analisar ocorrências de vogal média seguida de vogal alta nas sílabas subsequentes, tais como em menino $\sim$ minino, costume $\sim$ custume.

${ }^{3}$ O PHRS é coordenado pela professora Evellyne Costa, da UFSM, e está disponível para a comunidade acadêmica desde dezembro de 2011. 


\section{DESCRIÇÃO E ANÁLISE DOS DADOS}

\section{Appendix Probi}

Dentre os dados do Appendix Probi, verifica-se 9 casos de harmonia vocálica listados no Quadro 1 (à direita, estão os dados para a vogal anterior e à esquerda, os para a vogal posterior).

\section{Quadro 1 - Harmonia Vocálica no Appendix Probi}

\begin{tabular}{|l|l|}
\hline \multicolumn{1}{|c|}{ Vogal /e/ } & \multicolumn{1}{|c|}{ Vogal /o/ } \\
48.Byzacenus non Bizacinus - Bizâncio & $\begin{array}{l}\text { 25.formica non furmica - formiga } \\
\text { 50.dysentericus non dysintericus } \quad-\end{array}$ \\
75.formosus non formunsus - formoso \\
portador de desinteria \\
64.senatus non sinatus - senado \\
68.palearium non paliarium - celeiro \\
87.festuca non fistuca - palheira \\
189.bipennis non bipinnis - penugem \\
dupla rubigo - ferrugem
\end{tabular}

\section{Fonte: Appendix Probi}

Os trabalhos de Bisol (1981) e de Schwint (2002) apontam que a ocorrência de harmonia vocálica é condicionada por diverso fatores linguísticos, dentre os quais destacamos tipo de vogal, homorganicidade e contiguidade. Tipo de vogal refere-se à qualidade da vogal, se média alta posterior $(/ \mathrm{o} /)$ ou média alta anterior $(/ \mathrm{e} /)$; homorganicidade diz respeito à concordância da vogal-alvo do processo de harmonia vocálica (/e/ ou /o/) e da vogal-gatilho (/i/ ou /u/) quanto à anterioridade/posterioridade da língua; contiguidade faz menção à proximidade da vogal-gatilho em relação à vogalalvo.

No que se refere ao tipo de vogal, observam-se 6 dados em que a vogal e harmoniza-se (fistuca, Bizacinus, sinatus, bippinis, paliarium e dysintericus) e 3 casos nos quais a vogal o é alvo do fenômeno (furmica, rubigo e formunsus). De modo geral, os dados indicam que a vogal e sofre mais harmonização vocálica do que a vogal $\mathbf{o}$.

Dos 9 casos de harmonia vocálica registrados no Quadro 1, há 3 dados em que ambas as vogais são homorgânicas quanto ao traço anterior (bipinnis, palearium, dysintericus) e 1 caso de homorganicidade quanto ao traço posterior (formunsus); os demais dados são de combinações não-homorgânicas quanto à posição horizontal da língua: e/u (fistuca, Bizacinus, sinatus); o/i 
(rubigo, furmica). Os dados parecem mostrar que a homorganicidade não teria papel na harmonização vocálica. Dados do português falado atualmente apontam para um ligeiro favorecimento do fenômeno quando as duas vogais compartilham a mesma posição de anterioridade/posterioridade da língua.

Os dados do latim vulgar indicam que a vogal $\mathbf{u}$ motivaria mais a harmonização vocálica do que a vogal i. No entanto, de acordo com Schwindt (2002), a vogal i teria maior poder de elevação independentemente da vogal pretônica envolvida. Uma possível explicação para essa diferença seria a troca da vogal alta posterior das desinências -us, -um pela vogal temática o. Retomaremos essa questão quando tratarmos do português antigo.

Em 6 dados do Appendix Probi, a vogal alta localiza-se na sílaba imediatamente adjacente à vogal média (fistuca, Bizacinus, bipinnis, furmica, rubigo, furmunsus) e, nos demais dados, a vogal alta não é contígua à média. Chamamos a atenção para o fato de que aqui o papel da contiguidade não se mostra claro em virtude do pequeno número de dados, todavia a proximidade entre as vogais médias e as vogais altas é altamente favorecedora da harmonia vocálica tanto em dados do português antigo quanto do atual, como veremos mais adiante.

Observando as palavras listadas nesse glossário, percebemos, também, que há contexto favorecedor ao alçamento, contudo, esse não ocorre, como vemos nos exemplos em (1).

(1)

13. septizonium non septidonium

183. parentalia non parantalia

Há, ainda, casos de hipercorreção, o que reforça a instabilidade do sistema vocálico no que se refere à realização das vogais médias. Em (2), ilustramos essa questão.

(2)

116. delirus non delerus

144. dimidius non demidius

203. sirena non serena

\section{Orthographia, ou a arte de escrever, e pronunciar com acerto a língua portugueza, de Feijó (1739)}

Dentre as ocorrências de vogal média seguida de vogal alta, em sílabas subsequentes, observam-se 106 exemplos de vogal média anterior e 20 de vogal posterior. A seguir, apresentamos os dados para cada uma dessas vogais separadamente. 
Vogal média anterior

O número total de dados para essa vogal foi 106, dos quais 86 são homorgânicos quanto à posição horizontal da língua e 20 são nãohomorgânicos, como podemos ver no Quadro 2.

Quadro 2: Ocorrências de harmonia vocálica com a vogal /e/ divididas no que diz respeito à homorganicidade/não-homorganicidade

\begin{tabular}{|l|l|}
\hline Homorgânica & Não-homorgânica \\
\hline abastecido e não abasticido & abelhudo e não abilhudo \\
acontecido e não aconticido & abetumar e não abitumar \\
acontecimento e não aconticimento & atenuar e não atinuar \\
affeminar e não affiminar & aventurar e não avinturar \\
amenidade e não aminidade & betume e não bitume \\
amollecido e não amollicido & conteúdo e não contiudo \\
apercebido e não aprecibido & defumar e não difumar \\
acreditar e não acriditar & denunciação e não dinunciação \\
adversidade e não advirsidade & desculpa e não disculpa \\
alecrim e não alicrim & desculpar e não disculpar \\
appelido e não appilido & fechadura e não fichadura \\
arcebispo e não arcibispo & legumes e não ligumes \\
arcediago e não arcidiago & pendurar e não pindurar \\
atrevido e não atrivido & penuria e não pinuria \\
beneficiado e não binificiado & quentura e não quintura \\
bebedice e não bebidice & segurar e não sigurar \\
beneficencia e não benificencia & segundar e não sigundar \\
beneficio e não benificio & sepultar e não sipultar \\
collegiada e não colligiada & sepultura e não sipultura \\
collegial e não colligial & ternura e não tirnura \\
competidor e não compitidor & \\
compellir e não compillir & \\
competir e não compitir & \\
concebido e não concibido & \\
concedido e não concidido & \\
convertida e não convirtida & \\
debilidade e não dibilidade & \\
debilitar e não dibilitar & \\
decifrar e não dicifrar & \\
decidir e não dicidir & \\
dedicação e não didicação & \\
definição e não difinição & \\
\hline
\end{tabular}




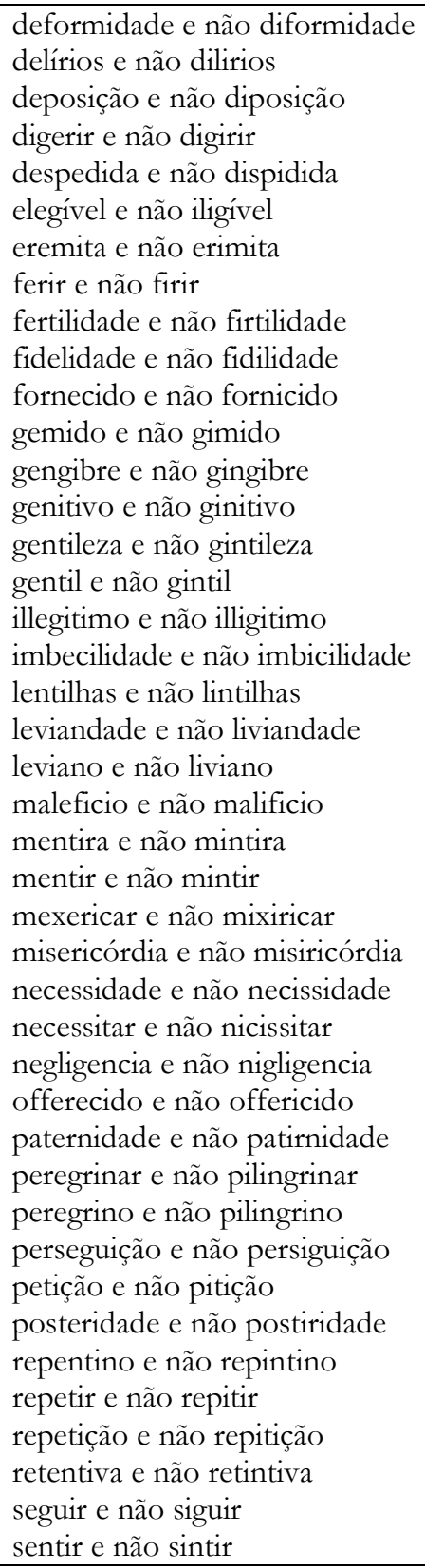


sentido e não sintido

sentinela e não sintinela

servir e não sirvir

severidade e não seviridade

sinceridade e não sinciridade

temeridade e não temiridade

verificar e não virificar

veridico e não viridico

vestimenta e não vistimenta

vestígio e não vistigio

vestir e não vistir

Fonte: Adaptado de Feijó (1739).

Diferentemente dos dados do Appendix Probi, há mais ocorrências de elevação desencadeadas por /i/ do que por /u/. Essa constatação vai ao encontro das observações sobre a língua falada feitas por Schwindt (2002), qual seja, de que o processo de harmonia vocálica é um fenômeno variável e não estagnado.

No Quadro 2, vemos também que 100 dados dizem respeito a palavras em que a vogal média é contígua à alta e 3, não-contígua. Dentre os 21 casos em que há duas vogais médias anteriores em sequência, em 7 casos houve elevação de ambas as vogais, como em dispidida, nicissitar, pilingrinar; nos demais casos, apenas a vogal média mais contígua à vogal alta sofreu elevação, como se vê em benificio, repitição, temiridade. Observamos ainda que, em 12 casos em que sequências de vogais /o/ e /e/ precedem uma vogal alta, nessa ordem, não há alçamento da vogal média mais distante da vogal-gatilho, como por exemplo, aconticido, amollicido, postiridade. Tais observações comprovam que a contiguidade exerce forte pressão para a ocorrência de harmonia vocálica. Os dados do latim vulgar já mostravam indícios da importância da adjacência entre a vogal-alvo e a vogalgatilho.

Vogal média posterior

O número total de dados para essa vogal foi 20 , dos quais 5 são homorgânicos quanto à posição horizontal da língua e 15 são nãohomorgânicos, como podemos ver no Quadro 3. 
Quadro 3: Ocorrências de harmonia vocálica com a vogal /o/ divididas no que diz respeito à homorganicidade/não-homorganicidade

\begin{tabular}{|l|l|}
\hline Homorgânica & Não-homorgânica \\
\hline acoflumar e não acuflumar & afocinhar e não afucinhar \\
costumar e não custumar & agonia e não agunia \\
doçura e não duçura & agoniar e não aguniar \\
tortulho e não turtulho & alcovitar e não alcuvitar \\
& amotinar e não amutinar \\
& amofinar e não amufinar \\
& borrifar e não burrifar \\
& boril e não buril \\
& cobrir e não cubrir \\
& desobrigar e não desubrigar \\
& lombrigas e não lumbrigas \\
& moribundo e não muribundo \\
motim e não mutim & recopilação e não recupilação \\
& sortida e não surtida \\
\hline
\end{tabular}

Fonte: adaptado de Feijó (1739)

Aqui também há mais casos de alçamento motivados por /i/ do que por $/ \mathrm{u} /$, o que corrobora observações anteriores.

Além disso, os dados para a vogal /o/ reforçam ainda mais a importância da adjacência entre as vogais envolvidas no processo, uma vez que, em todas as ocorrências de harmonia vocálica, as vogais são contíguas.

É importante mencionar que nos dados de Feijó (1739) existem casos em que há contexto para a ocorrência de harmonia vocálica, mas esta não se manifesta, por exemplo, em alforria, avenida, advocacia, academia, acessível, alegoria, analogia, animosidade, entre outros; fato já observado nos dados do Appendix Probi. Além disso, há casos em que não há elevação da vogal média, mas sim outros processos fonológicos, tais como metátese (abertura e não abretura) e apagamento (advento e não avento).

Essa variabilidade na realização das vogais, ora como médias, ora como altas, também aparece em casos de hipercorreção, ou seja, em contextos em que a vogal deveria ser alta e é pronunciada como média, como (3) ilustra. Observamos situação semelhante nos casos de abaixamento, exemplificados em (4).

(3)

\section{Bugiar e não bogiar}


Bugio e não bogio

Acumular e não accomular

Affigurar e não affegurar

(4)

Alimentar e não alementar

Abundar e não abondar

Acuar e não acoar

Observam-se ainda casos em que há alçamento da média pretônica sem motivação aparente, ou seja, na ausência de vogal alta subsequente, como vemos em (5).

(5)

Alfandega e não alfandiga

Algodão e não algudão

Almofada e não almufada

Alvejar e não alvijar

Beato e não biato

Camaleão e não camalião

\section{Corpora complementares: outras fontes do português histórico}

Com o intuito de acompanhar a harmonia vocálica em intervalos menores de tempo, foram coletados dados de português antigo, descritos a seguir.

O Corpus do Português: 45 milhões de palavras do século XIII ao século XX (DAVIES; FERREIRA, 2006) é um banco de dados online formado majoritariamente por textos literários. São registradas ocorrências de harmonia vocálica, como vemos no Quadro 4. Em virtude da ausência de uma normatização ortográfica, é possível encontrar dados que reflitam a fala.

Quadro 4: Ocorrências de harmonia vocálica extraídos do Corpus do Português

\begin{tabular}{|l|l|l|}
\hline Ocorrência & Obra - autor & Ano \\
\hline Minina & Obra poética - Luis & Séc. XVI \\
& Vaz de Camões & \\
\hline Minino & Peregrinação dr & 1603 \\
& Fernão Mendes & \\
& Pinto & \\
\hline Minino & A vida de Frei & 1606 \\
& Bartolomeu ros & \\
\hline
\end{tabular}




\begin{tabular}{|l|l|l|}
\hline & $\begin{array}{l}\text { Mártires - Luís de } \\
\text { Souza }\end{array}$ & \\
\hline Minino & $\begin{array}{l}\text { Adágios - Antonio } \\
\text { Delicado }\end{array}$ & 1651 \\
\hline Bugia & $\begin{array}{l}\text { Enfermidades da } \\
\text { lingua portuguesa - } \\
\text { Manuel José de } \\
\text { Paiva }\end{array}$ & \\
\hline Quirida & $\begin{array}{l}\text { Compêndio - Pe. } \\
\text { José Amaro da } \\
\text { Silva }\end{array}$ & 1838 \\
\hline Bugia & $\begin{array}{l}\text { Os Lobisomens - } \\
\text { Araujo Porto } \\
\text { Alegre }\end{array}$ & \\
\hline Bulir & $\begin{array}{l}\text { A Normalista - } \\
\text { Adolfo Caminha }\end{array}$ & 1893 \\
\hline Bulir & $\begin{array}{l}\text { Dom Casmurro - } \\
\text { Machado de Assis }\end{array}$ & 1899 \\
\hline Custume & $\begin{array}{l}\text { Diário Intimo - } \\
\text { Lima Barreto }\end{array}$ & 1900 \\
\hline Bulir & $\begin{array}{l}\text { O Matuto - } \\
\text { Franklin Távora }\end{array}$ & 1902 \\
\hline Bulir & $\begin{array}{l}\text { O Touro Negro - } \\
\text { Aluísio Azevedo }\end{array}$ & 1910 \\
\hline
\end{tabular}

Fonte: Adaptado do Corpus do Português: 45 milhões de palavras do século XIII ao XX (DAVIES; FERREIRA, 2006)

A seguir, descrevemos as ocorrências de harmonia vocálica em outras fontes do português histórico. $\mathrm{Na}$ obra de Fernão de Oliveira (1536) são registrados casos como surrir, durmir e bulir que, segundo o autor, eram confundidos com sorrir, dormir e bolir. Em Mattos e Silva (2009) estão descritos os seguintes casos de harmonização vocálica:

1) nos "Diálogos de São Gregório" (século XIV): meninice/mininice, vegiar/vigiar, desplizel/displizel, veuva/viúva, vendita/vindita, enterido/entirido, costume/custume, moimento/muimento e outoridade/outuridade;

2) nas "Cantigas de Santa Maria" (século XIII): pidimos, pidi, sirvia, firidas;

3) na gramática de João de Barros (século XVI): bibiam, mistiço, mininos e pirigos. 
No banco de dados PHRS (20 cartas pessoais) foi encontrado 1 registro de harmonia vocálica: acustumados.

A partir do conjunto de dados arrolados anteriormente, podemos perceber que algumas ocorrências repetem-se em obras e períodos diferentes, tais como mininos, custume e suas variantes. Os dados parecem apontar ainda para uma variação com posterior mudança: bolir em português antigo que passa a bulir em português atual. Dados como bogir, veuva, vegiar que passam a bugir, viúva e vigiar, respectivamente, também são exemplos dessa possível mudança.

Através dos corpora complementares, verificamos que a harmonia vocálica perpassa o continuum do latim vulgar ao português atual, referida por gramáticos e lexicógrafos, e encontrada em dados extraídos de textos literários. Conforme Mattos e Silva (2009, p. 34), "a elevação do timbre da pretônica por harmonização vocálica remonta o século XIII pelo menos e está certamente no dialeto padrão do século XVI".

No Quadro 5, apresentamos um panorama da incidência de harmonia vocálica desde o latim vulgar até os dias de hoje. Chamamos a atenção para o fato de que o número de formas harmonizadas tem aumentado ao longo do tempo.

Quadro 5: Quadro-resumo das ocorrências de harmonia vocálica nas fontes consultadas

\begin{tabular}{|l|l|l|l|}
\hline Fontes & Vogal /e/ & Vogal /o/ & Total \\
\hline Appendix Probi (séc. IV d. C.) & 6 & 3 & 9 \\
\hline Feijó (1739) fontes do português & 103 & 20 & 123 \\
\hline $\begin{array}{l}\text { Outras } \\
\text { histórico (até 1910) }\end{array}$ & 19 & 14 & 33 \\
\hline Schwindt (2002) & 2405 & 2335 & 4740 \\
\hline Total & 2533 & 2372 & 4905 \\
\hline
\end{tabular}

Fonte: Das autoras

\section{Considerações finais}

A análise de dados em que há elevação das vogais médias fornece resultados importantes para o estudo do sistema vocálico do português considerando-se o continum da língua. De fato, foi possível verificar que a harmonia vocálica remonta ao latim vulgar e que desde então se caracterizou como um processo variável. Essa instabilidade é observada até os dias de hoje, por isso, não estaríamos diante de uma mudança em curso, embora o número de formas harmonizadas tenha aumentado com o passar do tempo. 
Neste trabalho, observamos as seguintes características na realização de /e,o/ como /i,u/:

1) a harmonia da vogal /e/ é mais frequente do que a da vogal /o/;

2) a vogal /i/ desencadeia mais o fenômeno do que a vogal $/ u /$, independentemente de a vogal média ser homorgânica ou não à vogal-gatilho;

3) o fato de a vogal média estar adjacente à vogal alta é muito favorecedor da harmonia vocálica.

Para uma descrição mais abrangente do fenômeno, é necessário ainda ampliar os corpora do português histórico, o que será feito em análises futuras.

\section{REFERÊNCIAS}

AVELHEDA, A. C.; SILVEIRA, E. Vogais médias pretônicas: uma análise pancrônica. In: VII Congresso Internacional da Abralin, 7, 2011, Curitiba. Anais. Curitiba: UFPR. Disponível em: $<$ http://www.abralin.org/abralin11_cdrom/artigos/Anna_Carolina_Avelheda _2.PDF>. Acesso em: 10. jan. 2011.

BASSETO, B. Elementos de Filologia Românica. São Paulo: EDUSP, 2002.

BERLINCK, R.; BARBOSA, J.; MARINE, T. Reflexões teóricometodológicas sobre fontes para o estudo histórico da língua. Revista da Abralin, João Pessoa, v.7, n. 2, 2008.

BISOL, L. Harmonia vocálica: uma regra variável. $332 \mathrm{f}$. Tese (Doutorado em Letras). Faculdade de Letras, Universidade Federal do Rio de Janeiro. Rio de Janeiro - RJ, 1981.

CARVALHO, J. H. Nota sobre o vocalismo antigo português: valor dos grafemas $e$ e $o$ em sílaba átona. In: . Estudos Linguísticos. Coimbra: $\begin{array}{lllll}\text { Atlântica, } & \text { v. } & 2, & \text { p. } & 75-103,\end{array}$ CASTILHO, A. Análise multissistêmica das preposições do eixo transversal no português brasileiro: espaço /anterior/ / posterior. In: RAMOS, J. M.; ALKMIM, M. (Org.). Para uma história do português brasileiro. Belo Horizonte: Faculdade de Letras da UFMG, 2007.

CASTRO, I. Curso de história da língua portuguesa. Lisboa: Universidade Aberta, 1991.

COSERIU, E. Sincronia, diacronia e história. Rio de Janeiro: Presença; São Paulo: USP, 1979.

DAVIES, M.; FERREIRA, M. Corpus do português: 45 milhões de palavras do século XIII ao XX, 2006. Disponível em: $<$ http://www.corpusdoportugues.org >. Acesso em: 25. jan. 2012. FEIJÓ, J. M. Orthographia, ou a arte de escrever, e pronunciar com acerto a língua portugueza. Lisboa: S. Clara de Santarém, 1739. Disponível em: 
$<$ http://books.google.com.br/books?id=z7IGAAAAQAAJ\&printsec=frontc over\&hl=pt-

BR\&source $=$ gbs_ge_summary_r\&cad $=0 \# \mathrm{v}=$ onepage\&q\&f$=$ false $>$. Acesso em: 25. fev. 2012.

LABOV, W. On the mechanism of linguistic change. In: GUMPERZ, J.J; HYMES, D. Directions in sociolinguistics: the ethnography of communication. New York: Hold, Rinehart and Winstion, 1972.

MATTOS E SILVA, R. V. Como se estruturou a Língua Portuguesa? Perspectiva histórica da fonologia e da morfologia da língua portuguesa. Disponível em: <http://www.estacaodaluz.org.br/files/mlp/texto_10.pdf>. Acesso em: $28 . \quad$ fev. 2012. MONARETTO, V. O estudo da mudança de som no registro escrito: fonte para o estudo da fonologia diacrônica. Letras de Hoje, Porto Alegre, v.40, n.3., 2005.

OLIVEIRA, F. de. Gramática da lingoagem portuguesa. Edição crítica, semidiplomática e anastática. Lisboa: Academia das Ciências de Lisboa, 2000 (edição organizada por Amadeu Torres e Carlos Assunção).

POGGIO, R. Processos de gramaticalização de preposições do latim ao português. Salvador: Edufba, 2002.

SCHWINDT, L. C. A regra variável de harmonização vocálica no RS. In: BISOL, L.; BRESCANCINI, C. (Org.). Fonologia e variação: recortes do português brasileiro. Porto Alegre: EDIPUCRS, 2002.

WEINREICH, U.; LABOV, W.; HERZOG, M. Fundamentos empíricos para uma teoria da mudança linguística. São Paulo: Parábola, 1968.

WETZELS, L. Mid vowel neutralization in Brazilian Portuguese. Cadernos de Estudos Linguísticos, n. 23, p. 19-55, jul/dez. 1992. 